denklichen Mittel anzuwenden, um diese Hänte zu zerstören, zu lösen und herauszubefördern. Obwohl beide Krankheitsprocesse gegenwärtig vorn anatomischen und wohl auch klinischen Standpunkt auseinander gehaltell werden, indem dem Croup ein rein entzündlicher, der Diphtherie ein infectiöser zur Sepsis neigender Charakter zugesprochen wird, können doch Wenige sich der Versuchung erwehren, schon im Initialstadium der Diplltherie, wo die charakteristischen Beläge nur die Rachenorgane einzunehmen pflegen, die ersteren sofort auf das Energischste zu bekämpfen, und zwar hauptsächlich in der Absicht, ihr Herunterkriechen nach dem Kehlkopf zu verhindern.

Seit Verallgemeinerung der Anschauungen über die bacterielle Aetiologie auch dieser Krankheit werden gegen den vermeintlichen Diphtheriepilz aus dem mikrobociden Arsenal alle Waffen der Reihe nach, wie sie von der chirurgischen Tactik gegen Wundinfectionen erprobt worden, in den Kampf gebracht. Wenn nun aber die bisherigen bacteriologischen Forschunge॥ ergeben, dass das diphtherische Gift kein einheitliches ist, wenn schon Löffler ausser einem Bacillus auch Mikrococcen in den diphtherischen Exsudaten, spăter Crooke und nach ihm Fraenkel und Freudenberg in der scarlatinösen Diphtherie solche als Streptococcus pyogenes Rosenbach charakterisirte Coccen aufgefunden, und zwar letztere auch in den infiltrirten Lymphdrüsen und inneren Organen an Diphtherie Gestorbener nachgewiesen haben, und diese Streptococcen als Vermittler einer secundären Infection ansprechen, so wird man wohl unter Berücksichtigung der klinischen Erscheinungen nicht irre gehen, wenn man auch für die idiopathische Diphtherie eine primäre diphtherische, membranbildende, und eine secundäre, septische Infection annimmt.

Die erste, bacillöse Infection, kann wohl, so lange ihre Producte auf den Rachen beschränkt bleiben, keine direkte Gefahr heraufbeschwören, sie wird erst bedrohlich mit dem Heruntersteigen nach dem Kehlkopfe.

Da nach den Thierexperimenten Löffler's die Uebertragung von Diphtheriebacillen auf gesunde Schleimhänte ohne nachtheilige Folgen bleibt, und nur an vom Epithel entblössten Stellen die charakteristischen Beläge hervorruft, so dürfte man wohl, um die weitere Ausdehnung der Bacillen, vornehmlich nach dem Kehlkopf zu verhüten, richtiger zu Werke gehen, 'wenn man anstatt der üblichen Versuche, die fertigen Membranes zu zerstören oder zu entfernen, was ohne Schädigung der benachbarten, gesunden Epithelien schwerlich zu vollbringen wäre, alle Sorgfalt darauf verwendet, die angrenzenden Schleimhautflächen in ihrer Integrität zu erhalten. Die diphtherische Rachenmembran kann, wenn die Coagulationsnekrose nicht über die Epitheldecke hinaus tiefer in's Gewebe der Schleimhaut hineingreift, nicht nur ganz harmlos verbleiben, sondern sogar, wenı sie zusammenhängend und fest bleibt, einen Schutzmantel gegen die bevorstehende, secundäre Invasion der Sepsis erregenden Streptococcen bilden.

Noch neverdings habe ich wieder einen derartigen Fall von Rachendiphtherie bei einem 30jährigen Tapezierer zu beobachten Gelegenheit gehabt, welcher an Halsschmerzen mit geringer Störung des Allgemeinbefindens erkrankt, aber wegen der ominösen Localaffection sofort der Anstalt überwiesen worden war.

Beide Mandeln, Gaumenbögen und das Zäpfchen waren mit einer grauweisslichen, festzusammenhängenden Membran auf stark geröthetem Schleim hautgrunde bedeckt, die Unterkieferdrüsen mässig geschwollen, die Temperatur gegen $39^{\circ}$, subjectives Befinden ausser Schmerzen beim Schlingen und Appetitmangel wenig alterirt.

Ord.: ein Löffel Ol. Ricini und Sol. Natrii chlorati $(5,0) 500,0$, Tr. Jodi 2,0 - alle $1 / 4$ Stunde $1 / 2$ Esslöffel langsam gurgelnd herunterzuschlucken. Am folgenden Tage nach mehreren ergiebigen Stuhlausleerungen Temperatur normal, der Belag der Ausdehnung nach unverändert, nur auf den Mandeln etwas dünner erscheinend, die umgrenzende Schleimhaut weniger geröthet, die Unterkieferdrüsen weicher. Am dritten Tage fühlt sich Patient gesund und äussert Verlangen nach Entlassung, wird aber zurückgehalten, weil der diphtherische Belag noch fortbesteht, aber ganz allmählich, wie ein schmelzendes Schneefeld, immer schmäler unı dünner wird unter Zurücklassung ganz normaler Schleimhaut, der Art, dass der letzte Rest des Belages auf dem Zäpfchen erst am 7. Tage völlig verschivand.

Fin so milder Verlauf der Rachendiphtherie begegnet uns selten, zeigt indessen, wie unnöthig es ist, gegen die diphtherischen Exsudate selbst energisch vorzugehen.

Gewöhnlich zerfallen die Beläge schnell und hinterlassen je nach dem Umfange und der Tiefe der voraufgegangenen Nekrose in Fläche und 'T'iefe ausgedehnte putride Ulcerationen mit reactiver Entzündung der R̈̈nder, an welchen schmutzig grane Anflüge sich immer wieder erneuern

Der Streptococcus hat sein verheerendes Regiment begonnen, vergeblich suchen ihn die strotzend sich infiltrirenden Lymphdrüsen der Halsgegend aufzuhalten, er drängt in die Blutbahn und vergiftet innere wichtige Lebensorgane. Während bei plötzlich ausbrechenden Epidemieen die Erstlingsfälle im Verlaufe weniger Tage an Aer septischen Allgemeininfection oder durch Verlegung der Luftwege, jeder Therapie spottend, 7u Grunde gehen, pflegen die später auftretenden und die Erkrankungen in grösseren Städten, wo das Krankheitsgift, wie hier in Posen fast nie ganz erlischt, und die Einwohner gewissermaassen an dasselbe acclimatisirt erscheinen, einen milderen Charakter anzunehmen und für unsere therapeutischen Maassregeln günstigere Chancen zu eröffnen.

Für die Therapie der Diphtherie, als einer vorwiegend sich darstellenden Mischinfection, würden sich demnach zwei Aufgaben ergeben: Die erste bestände in der Verhütung der Ausbreitung des exsudativen Processes anf die. Luftwege, die zweite in der Bekämpfung der hinzutretenden septischen Infection. Zu ersterem $\mathrm{Z}$ wecke würde es darauf ankommen, die reactive Entzündung der fast ausschliesslich primär afficirten Rachenschleimhant möglichst in Schranken zu halten, ohne an der diphtherischen Membran selbst irgendwie zu rütteln.

Ohme den Werth nach der Haut ableitender, warm werdender Wasserkopfsstenose forderte die Aerzte heraus, ihren Hauptangriff gegen die las Kehlkopfsinnere verlegenden falschen Membranen zu richten ind alle er-

\section{Therapeutische Mittheilungen} Autorreferat von Dr. v. Kaczorowski in Posen. Einiges hindeuten, was man bei der Behandlung der Diphtherie lieber zu en hätte.

Die Therapie der Diphtherie ist von vornherein dadurch anf Abw celet worden, dass Kehlkopfscroup mit Kehlkopfsdiphtherie zusamm 
Unsehläge nu den llals, des hänfigen Genusses eiskalten, sterilisirten ouler Quellwassers in Frage stellen zu wollen, würde ich ein viel grösseres Gewicht auf alltägliche leichte Purgirung des Kranken, allerdings nur mit Hülfe des harmlos und sicher wirkenden Ricinusöls, legen, indem reichlichere Darmausleerungen ganz entschieden die Hyperämie der Rachenschleimhaut lierabsetzen, ohne die schwächende Nebenwirkung der Blutentziehungen zu äussern. Ferner wäre das ganze Krankheitsfeld, unter Umständen der ganze Nasenrachenraum recht häufig nit einer desinficirenden aber 7.ugleich die Resistenzfähiglseit der Epithelzellen leicht anregenden, absolut ungiftigen Flüssigkeit zu berieseln, welche, um die tiefer gelegenen Rachentheile zu erreichen, langsam verschlıckt event. durch die Nase eingespritzt werden muss.

$\mathrm{Zu}$ diesem $\mathrm{Z}$ wecke würde sich ganz vorzüglich das vielfach angewandte cllorsaure Kali eignen, wenı nicht die Erfalırung, dass es in den hier erforderlichen grossen Quantitäten Vergiftungserscheinungen hervormfen kïnne, der Anwendung dieses Mittels ernstliche Bedenken entgegenstellte. Aus diesem Grunde ersetze ich dasselbe durch die oben erwähnte Jor-Kochsalzlösung, welche vor dem Kali chloricum noch den Vorzug hat, keiu Brennen im Halse zu erregen und den Widerwillen gegen Nahrungs-. anfnahme zu bekämpfen.

Diese Lösung wird alle 1/4 Stunden zum laalben bis gan\%en Esslöffel gereicht, von Kindern gern genommen und ohne die geringsten schädlichen Nebenwirkungen Wochen lang gut ertragen. Unter dieser Behandlung habe ich in leichteren Fällen, wie in dem oben citirten, entweder gar keinen ulcerösen Zerfall der Membranen eintreten, oder oberflächliche Ulcerationen ohne septische Allgemeininfectionen binnen einigen Tagell iı Heilıng übergeben gesehen.

In schwereren Erkrankungsfällen mit putridem Zerfall der Localaffection und liereinbrechender Septhämie werden nebenbei noch energischere Antiseptica zu versuchen sein, docl dïrften lier ganz besonders nur der aromatischen Gruppe angehörende Mittel am Platze sein, welche zugleicl stimulirend auf die Herzthätigkeit einwirken und mit der Exspirationsluft ansgesclieden die Respirationssclleimhaut gewissermaassen desinficiren.

Die in allen adynamischen Krankheiten bewährte Combination voll Camplier mit Benzoësäure lasse ich $1-2$ stündlich in schwerem Ungarweil oler Cognac bis rum Nachlass der gefahrdrohenden Erscheinungen nehmen, und glaube, dass sie mindestens ebensoviel wie das Terpentinöl leistet, ohne den Magen und die Nieren zu behelligen.

Vor Allem aber möclite ich in der Diphtheriebehandlıng vor der Anwendımg der Mercurialien, namentlich des in der Wundbehandlung leider noclı so beliebten Sublimats warueu. In einer von voluherein zur Sepsis tendirenden Krankheit wie der Diphtherie sollte ein Mittel, welches, abgesehen von der Stomatitis, unter Umständen die gefahrdrohendste septische Entründung des Darms zu erregen vermag, als ein zweischneidiges Schwert alisolit perliorrescirt werden.

Jass kräftige Ernährung der Patienten nit. Milch und edlem Alkohol nud stete Zuführıng frisclıer Juft ohne Rücksicht der Jalıreszeit bei einem so scllweren Allgemeinleiden unerlässlich sind, glanbe ich als selbstverständlicl annehmeı zu können. Eine. Mortalitütsstatistil der so von mir belandelten Diplitherietälle wolle man nir erlassen, weil iclı eine solche für den Werth einer Behandlıngsmethode bei einer Krankheit von so wechselnder Intensität, wie der Diphtherie, nicht für maassgebend erachte. Fulminante Diphtheriefälle, welche wohl stets jeder Behandlung Hohn sprechen werden, sinıl mir lö̈chst selten begegnet. Viele Hunderte von Mittelfällen, darunter auch ein Fall eines 4 jăhrigen Knaben, bei welchem unverkennbare Anzeichen von Kehlkopfsstenose zur 'Tracheotomie aufmufordern sclienen, habe i. $\cdot$ lı mit wenigen Ausnahmen in Heilnug übergehen sehen

Nachtrag. lis kann wohl als anffällig be\%eiclnnet. werden, dass bei der in letzter Zeit. verallgemeinerten Richtıng, die Diphtherie mit antiseptisclıen Mittelı tu belıandeln, das Jod, dieses älteste, wenngleich früher unter anderer Firma gefïhrte verhältuissmässig harmloseste und doch sehr thatkräftige Antibactericun so sehr ignorirt worden ist. Vielleicht dürfte diese Mittheihng ncben den von Stepp nud Zimmermann in dieser Wochenschrift veröffentlichten Beobaclitungen über die Behandhng der biphtherie mit .Jorlkalium diesen alten Freunde \%ahlreichere Aulünger gewimnen.

- Dr. C. Roese empfiehlt in dem Octoberheft der Therapeutischen Mitheilungen das Terpentinöl bei Diphtherie, nachdem er 60 Fäle damit hehandelt hatte. Wr hatte ca. 50 Jodesfälle. Das T'erpentinöl wurde theeloffelweise gegeben, drei Mal tüglich. Als Corrigeus wurde Spirit. atether. $1 \mathrm{~g}$ anf $10 \mathrm{~g}$ 'Terpentinöl benutzt; daneben gab Roese 2stïndlich 1 Essloffel einer $2 \%$ Lösung von salicylsaurem Natr.; ansserdem wandte or Fisblase an und Gurgelıngen mit $1 \%$ warmer Lösung von chlorsaurem Kali. Die subjectiven und objectiven Krscheinungen nahmen bei dieser Therapie ab. Erstickungsgefalır trat nur in einem Falle anf und damit die Nothwendigkeit der Tracheotomie. Pinselungen wurden niclit angewanilt. Bei Anämischen, Decrepiden und Zuckerkranken geschah die'Terpentinilverabreichung mit grosser Vorsicht. In allen Fällen daneben eine roboriłende Diät. Nach Eintreten der Fieberfreiheit und nacl Besserung der Jocalen Erscheinungen wurde das Terpentinöl ausgesetzt. Gewönlich genïgten 15-20 g; es wurden aber in einzelıen Fällen $60 \mathrm{~g}$ nöthig. Illtoxicatiouen sind nie beobachtet worden.

- T. Chazeaud giebt bei Phthisis mit gutem Erfolge das Morrhuol, eine Mischung von braunem Leberthran mit 90\% Kölpergewicht und Harnstoff sollen danach steigell, der Husten abnehmen. Ferner einpfiehlt er dasselbe Medicament gegen Scrophulosis und Rhachitis. Es darf nur in Kapseln genommen werden. Cha\%eaud giebt 2-4 Kapselı (währeud der Mahlzeit), fïr Kinder von 12-15 Jalıren, 6--8 Kapselı für Elwachsene, 8 Kapselı entsprechen ungefähr $50 \mathrm{~g}$ braunem Leberthran. Nach reichlicher Inose tritt zuweilen Akne. alf. (Thèse de Paris 1887.) 